\title{
Predictive value of the aspartate aminotransferase to platelet ratio index for parenteral nutrition associated cholestasis in extremely low birth weight infants
}

\author{
Ji Hye Hwang and Mi Lim Chung ${ }^{*}$ (1)
}

\begin{abstract}
Background: Parenteral nutrition (PN) improves the survival of premature infants. However, prolonged PN increases the risk of PN-associated cholestasis (PNAC).

Objective: We aimed to evaluate the predictive value of aspartate aminotransferase (AST)-to-platelet ratio index (APRI) for PNAC in infants with extremely low birth weight (ELBW, birth weight $<1000 \mathrm{~g}$ ) infants.

Methods: We retrospectively reviewed the medical records of ELBW infants from March 2010 to February 2017. Clinical data and the serial APRI, AST, alanine aminotransferase (ALT), AST-to-ALT ratio, and direct bilirubin (DB) were analyzed. PNAC was diagnosed in infants with a history of PN for at least 2 weeks and direct bilirubin concentrations $>2 \mathrm{mg} / \mathrm{dL}$ after other causes of neonatal cholestasis were excluded.
\end{abstract}

Results: Among the 179 eligible ELBW infants, 56 (31.3\%) were diagnosed with PNAC. APRI significantly differed between infants with PNAC and those without PNAC. The best APRI cut-off point was 0.410 at 2 weeks after the start of PN (area under the receiver operating characteristic curve $=0.752, p<0.05$; positive predictive value, 50.6\%; negative predictive value, $84.1 \%$ ).

Conclusion: APRI at 2 weeks after PN could be a reliable predictor of PNAC development in ELBW infants on PN.

Keywords: Aspartate aminotransferase to platelet ratio index, Parenteral nutrition, Parenteral nutrition-associated cholestasis, Extremely low birth weight infants

\section{Background}

Parenteral nutrition (PN) is essential for improving the growth and development of premature infants before enteral feeding can be established. However, long-term $\mathrm{PN}$ can also increase the risk of various $\mathrm{PN}$-associated hepatobiliary complications $[1,2]$. PN-associated cholestasis (PNAC) is the most common clinical manifestation of $\mathrm{PN}$-associated liver disease in preterm infants. The pathogenesis of PNAC is considered multifactorial. Several identified risk factors associated with PNAC are known; prematurity, small for gestational age, long duration of PN, sepsis, necrotizing enterocolitis (NEC), composition of PN solutions and a delay in enteral feeding $[3,4]$.

\footnotetext{
* Correspondence: forevery52@naver.com

Department of Pediatrics, Haeundae Paik Hospital, Inje University College of Medicine, 875, Haeundaero, Haeundae-gu, Busan 48108, Korea
}

Though most cases of PNAC resolve with enteral nutrition [5], progressive hepatic failure eventually can lead to death in some patients. Therefore, early identification of groups at risk of PNAC helps with an earlier adjustment in $\mathrm{PN}$ to decrease the risk of progressive to severe liver dysfunction.

The diagnosis of PNAC is made by checking the increased levels of direct bilirubin (DB). It is very simple and inexpensive. However, there is a limit to predict the development of PNAC by tracking values of $\mathrm{DB}$ alone. In many patients, the level of $\mathrm{DB}$ did not increase gradually. Even, it suddenly increase up to the point to diagnose PNAC. Therefore, we sought to find a new way to predict the PNAC. Numerous studies have demonstrated that the aspartate aminotransferase (AST)-to-platelet ratio index (APRI) is a reliable marker of liver fibrosis 
in adult patients [6,7]. Although studies are limited, the APRI has been investigated as a marker of hepatic fibrosis in chronic liver disease, hepatitis, and biliary atresia in the younger population [8-11]. The histopathology of PNAC has been described as a progression from bile duct proliferation to portal inflammation to bridging fibrosis to cirrhosis [12, 13]. Hence, we assumed that APRI also can be applied in PNAC of neonates. Only one study evaluated the predictive value of APRI for PNAC in premature infants, to date [14] and it enrolled a limited number of preterm infants with intestinal perforation.

This study was conducted to evaluate the predictive value of the APRI for PNAC in infants with extremely low birth weight (ELBW).

\section{Methods}

\section{Subjects}

We reviewed the medical records of ELBW infants, with a birth weight of less than $1000 \mathrm{~g}$, who were admitted to the NICU at Haeundae Paik Hospital, Busan, Korea between March 2010 and February 2018. The inclusion criteria were ELBW infants who received PN for at least 2 weeks and survived for more than 4 weeks. We excluded infants who had severe congenital anomalies, chromosomal abnormalities or clinically apparent congenital infections. Infants with other causes of cholestasis including hypothyroidism, gallstone were excluded and infants with congenital platelet disorder were excluded. We also excluded infants who were transferred to other hospital.

\section{Methods}

PNAC was defined as those with a direct bilirubin concentration $>2.0 \mathrm{mg} / \mathrm{dL}$ without other identifiable causes of cholestasis except for PN. We excluded the data when there was a temporary increase in DB accompanying sepsis and shortly resolved at follow up tests.

We collected basic demographic data and reviewed clinical variables including respiratory distress syndrome, patent ductus arteriosus, NEC, sepsis, transfusion history, surgery, ventilator care duration, and brochopulmonary dysplasia (BPD). NEC was defined as Bell's criteria stage two or greater. BPD was defined as a need for oxygen at 36 weeks of postmenstrual age. Maternal data were also reviewed. Data of nutritional support were also collected including the number of days until the initiation of enteral feeding, the time points at which half $(60 \mathrm{cc} / \mathrm{kg} /$ day $)$ and full $(120 \mathrm{cc} / \mathrm{kg} /$ day $)$ enteral feeding were reached and the number of days of total PN, and types of PN solutions.

The laboratory findings were reviewed to determine levels of total bilirubin (TB), DB, and liver enzymes including AST and alanine aminotransferase (ALT). The APRI was calculated from the equation according to Wai et al. [15] as follows: (AST/upper normal limit of
AST)/platelet count $\left(10^{9} / \mathrm{L}\right) * 100$, and upper normal limit of AST value was defined as $40 \mathrm{U} / \mathrm{L}$. We analyzed laboratory results in each time point as 1,2 , and 3 weeks after starting PN.

\section{Nutrition protocol}

Though it was varied according to the change of guidelines of our unit and the tolerance of the individual patient, common nutritional supplementation principle was as following and this methodology was used also from a previously work [16].

\section{Enteral nutrition protocol}

The starting enteral feeding volume was $10-20 \mathrm{~mL} / \mathrm{kg} /$ day divided into doses administered every $3 \mathrm{~h}$ and increased by $10-20 \mathrm{~mL} / \mathrm{kg} /$ day according to the baby's tolerance until full enteral feeding $(120-160 \mathrm{~mL} / \mathrm{kg} /$ day $)$ was achieved. We fed the ELBW infants either human milk or premature infant formula. After the enteral feeding volume reached $100 \mathrm{~mL} / \mathrm{kg} /$ day, breastmilk was fortified with a human milk fortifier.

\section{Parenteral nutrition protocol}

Proteins The infants were started at $0.5 \mathrm{~g} / \mathrm{kg}$ just after birth. The dose was increased by $0.5 \mathrm{~g} / \mathrm{kg} /$ day increments every day to a maximum dose of $3.0-4.0 \mathrm{~g} / \mathrm{kg} /$ day according to the baby's tolerance. From 2016, we administered $1.5 \mathrm{~g} / \mathrm{kg} /$ day as starting dose of parenteral amino acid and increased rapidly by $1.0 \mathrm{~g} / \mathrm{kg} /$ day to reach maximum concentration of $4.0-4.5 \mathrm{~g} / \mathrm{kg} /$ day.

Carbohydrates The infants were started at $7.0-8.0 \mathrm{~g} / \mathrm{kg} /$ day just after birth. The dose was increased by $1.0-2.0 \mathrm{~g} /$ $\mathrm{kg} /$ day every day according to the baby's tolerance to a maximum dose of $15.0-18.0 \mathrm{~g} / \mathrm{kg} /$ day.

Lipids Intravenous lipid emulsion was started at $0.5 \mathrm{~g} /$ $\mathrm{kg} /$ day on day two and was increased at a dose of $0.5 \mathrm{~g} /$ $\mathrm{kg} /$ day according to tolerance to a maximum dose of $3.5 \mathrm{~g} / \mathrm{kg} /$ day. Beginning in March 2010, Lipo MCT 20\% (Dong guk Pharm, Seoul, Korea) was used as the primary parenteral lipid solution. Between April 2011 and January 2013, Intralipid 20\% (Fresinius Kabi, Cheshire, UK) was used. Since January 2013, SMOF lipid (Fresenius Kabi, Bad Homburg, Germany) has been used in our NICU. After 2017, Omegaven (Fresinius Kabi, Cheshire, UK) was used as rescue therapy in patients with a diagnosis of PNAC. It was administered twice a week or every other day and was taken with SMOF lipid.

\section{Statistical analyses}

Data are presented as frequencies with percentages for the categorical variables and mean \pm standard deviation 
for continuous variables. Differences in participant characteristics were compared across subgroups with a Chi-square test or Fisher's exact test for categorical variables and independent test or Mann-Whitney's U test for continuous variables as appropriate. To check for normal distribution, we used Shapiro-Wilk's test. Univariate and multivariate analyses, using logistic regression, were performed in order to identify prognostic factors that were independently related to PNAC and death. In addition, the receiver operating characteristic (ROC) curve was performed to assess the sensitivity and specificity for PNAC. All statistical analyses were carried out using SPSS 24.0 and $p$ values less than 0.05 was considered statistically significant.

\section{Results}

Basic demographic and clinical characteristics

A total of 203 ELBW infants were admitted during the study period and 184 of these infants met the inclusion criteria. We excluded 5 infants. Four infants were transferred out to other hospital and one infant was diagnosed with an acquired cytomegalovirus infection. Finally, a total of 179 infants were enrolled in this study, and 56 (31.3\%) were diagnosed with PNAC at $36.16 \pm 17.67$ days after birth (Fig. 1). Table 1 shows various clinical factors associated with the development of PNAC. Composition of
PN solutions; use of fish-oil based lipid emulsion; and maximum concentrations and cumulative dose of macronutrient including carbohydrate, amino acids, and lipids were not associated with PNAC (data not shown).

\section{Laboratory test results}

Figure 2 shows the trends of laboratory test results at 1 , 2, and 3 weeks after PN with respect to PNAC. DB and APRI significantly differed between infants with PNAC and without PNAC at each time point and TB and AST also differed between groups at 3 weeks (Table 2). ROC curves for TB, DB, AST, ALT, AST/ALT, and APRI at 1, 2, and 3 weeks of age are presented in Fig. 3.

\section{Risk factors associated with PNAC}

Figure 3 shows the Receiver operating characteristic (ROC) curves of the DB, APRI to predict PNAC at each time points. Various clinical factors and laboratory test results were associated with the development of PNAC. Finally, the duration of $\mathrm{PN}$ and hospitalization, $\mathrm{DB}$ and APRI at 2 weeks were determined to be independent risk factors for PNAC in the multivariate logistic regression analysis (Table 3). At 2 weeks after PN, DB $>0.70$ and APRI $>0.41$ are cut-off points for prediction of PNAC has a $50.0 \%$ sensitivity, $91.7 \%$ specificity, $75.7 \%$ positive predictive value (PPV), and 78.1\% negative predictive value (NPV) (Table 4).

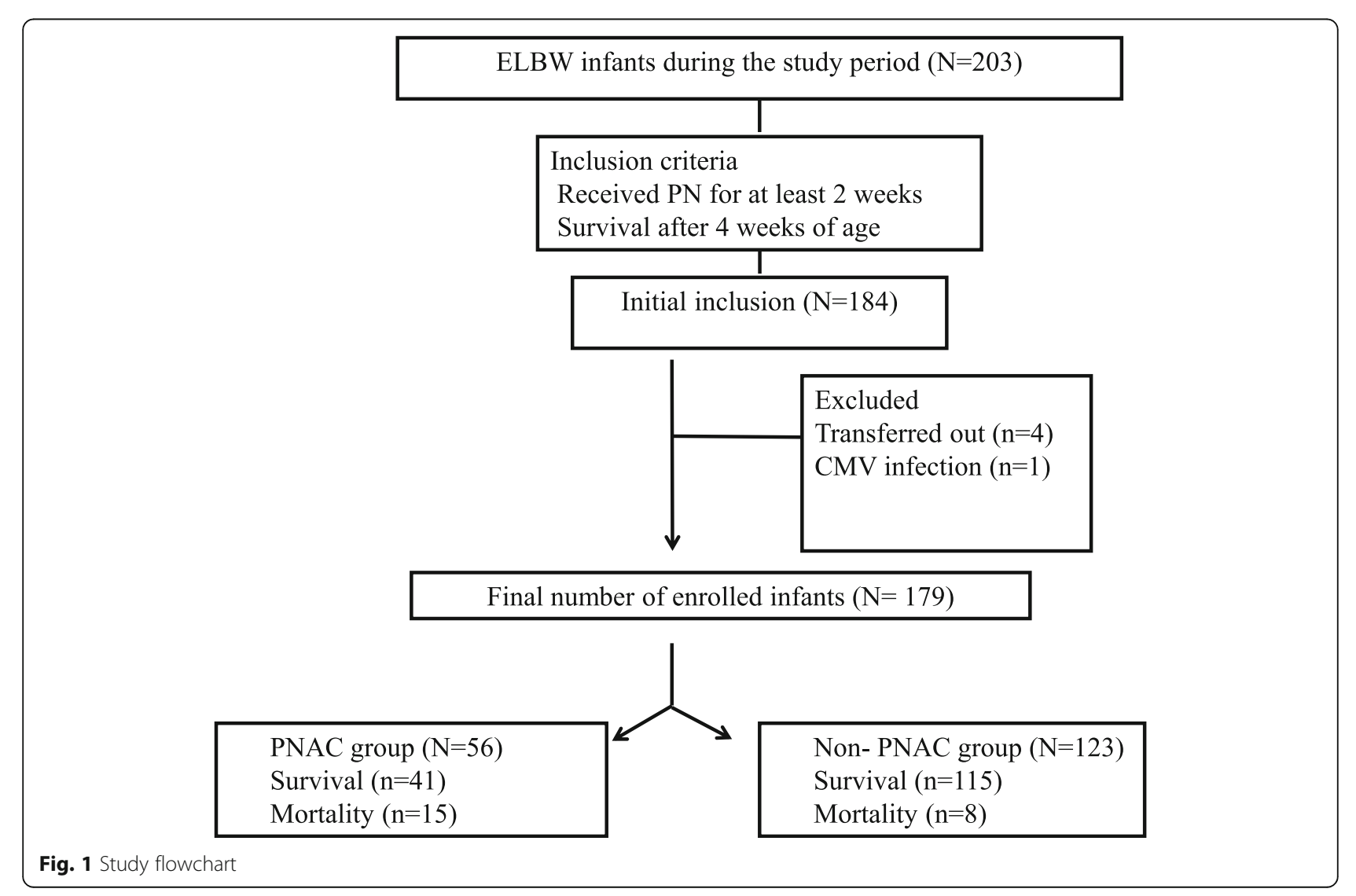


Table 1 Analysis of risk factors affecting PNAC

\begin{tabular}{|c|c|c|c|}
\hline \multirow[t]{2}{*}{ Variable } & \multicolumn{3}{|l|}{ PNAC } \\
\hline & Yes & No & $P$-value \\
\hline \multicolumn{4}{|l|}{ Gestational age (weeks) } \\
\hline Mean \pm SD & $26.07 \pm 2.23$ & $26.78 \pm 2.32$ & $.035^{2}$ \\
\hline \multicolumn{4}{|l|}{ Birth weight (gram) } \\
\hline Mean \pm SD & $737.68 \pm 151.71$ & $824.72 \pm 160.26$ & $.001^{2}$ \\
\hline Hospital days & $116.86 \pm 56.96$ & $94.34 \pm 37.46$ & $.003^{2}$ \\
\hline \multicolumn{4}{|l|}{ IUGR } \\
\hline Yes & $20(35.7)$ & $30(24.4)$ & $.117^{1}$ \\
\hline No & $36(64.3)$ & $93(75.6)$ & \\
\hline \multicolumn{4}{|l|}{ Sex } \\
\hline Male & $27(48.2)$ & $55(44.7)$ & $.663^{7}$ \\
\hline Female & $29(51.8)$ & $68(55.3)$ & \\
\hline Apgar score $1 \mathrm{~min}$ & $4.38 \pm 1.61$ & $4.82 \pm 1.31$ & $.085^{2}$ \\
\hline Apgar score 5 mins & $6.70 \pm 1.29$ & $6.93 \pm 0.98$ & $.230^{2}$ \\
\hline Ventilator duration (days) & $55.79 \pm 47.23$ & $29.26 \pm 25.69$ & $.000^{2}$ \\
\hline \multicolumn{4}{|l|}{ PDA } \\
\hline Surgical ligation & $19(33.9)$ & $22(17.9)$ & $.018^{1}$ \\
\hline Others & $37(66.1)$ & $101(82.1)$ & \\
\hline \multicolumn{4}{|l|}{ ROP } \\
\hline Laser or bevacizumab inj. & $38(67.9)$ & $59(48.0)$ & $.013^{1}$ \\
\hline Observation & $18(32.1)$ & $64(52.0)$ & \\
\hline \multicolumn{4}{|l|}{ Head ultrasonography } \\
\hline Normal & $35(62.5)$ & $87(70.7)$ & $.273^{7}$ \\
\hline Abnormal & $21(37.5)$ & $36(29.3)$ & \\
\hline \multicolumn{4}{|l|}{ BPD } \\
\hline Yes & $45(80.4)$ & $67(54.5)$ & $.001^{1}$ \\
\hline No & $11(19.6)$ & $56(45.5)$ & \\
\hline \multicolumn{4}{|l|}{ NEC } \\
\hline Yes & $27(48.2)$ & $15(12.2)$ & $.000^{7}$ \\
\hline No & $29(51.8)$ & $108(87.8)$ & \\
\hline \multicolumn{4}{|l|}{ Sepsis } \\
\hline Yes & $40(71.4)$ & $61(49.6)$ & $.006^{1}$ \\
\hline No & $16(28.6)$ & $62(50.4)$ & \\
\hline \multicolumn{4}{|l|}{ Gl surgery } \\
\hline Yes & $19(33.9)$ & $9(7.3)$ & $.000^{7}$ \\
\hline No & $37(66.1)$ & $114(92.7)$ & \\
\hline \multicolumn{4}{|l|}{ TPN days } \\
\hline Mean \pm SD & $74.13 \pm 50.62$ & $42.38 \pm 31.74$ & $.000^{2}$ \\
\hline \multicolumn{4}{|l|}{ Feeding start (days) } \\
\hline Mean \pm SD & $4.36 \pm 3.25$ & $3.86 \pm 2.60$ & $.234^{2}$ \\
\hline Days to achieve full enteral feeding (days) & $56.24 \pm 22.36$ & $35.06 \pm 15.95$ & $.000^{2}$ \\
\hline \multicolumn{4}{|l|}{ Type of formula } \\
\hline Breast milk & $20(37.7)$ & $73(59.8)$ & $.007^{1}$ \\
\hline Others & $33(62.3)$ & $49(40.2)$ & \\
\hline
\end{tabular}

Abbreviations: IUGR intrauterine grow retardation, PDA patent ductus arteriosus, ROP retinopathy of prematurity, BPD bronchopulmonary dysplasia, NEC necrotizing enterocolitis, TPN total parenteral nutrition, PNAC parenteral nutrition-associated cholestasis

${ }^{1} P$ values were derived from chi-square test

${ }^{2} P$ values were derived from Mann-Whitney's $U$ test. Shapiro-Wilk's test was employed for test of normality assumption 


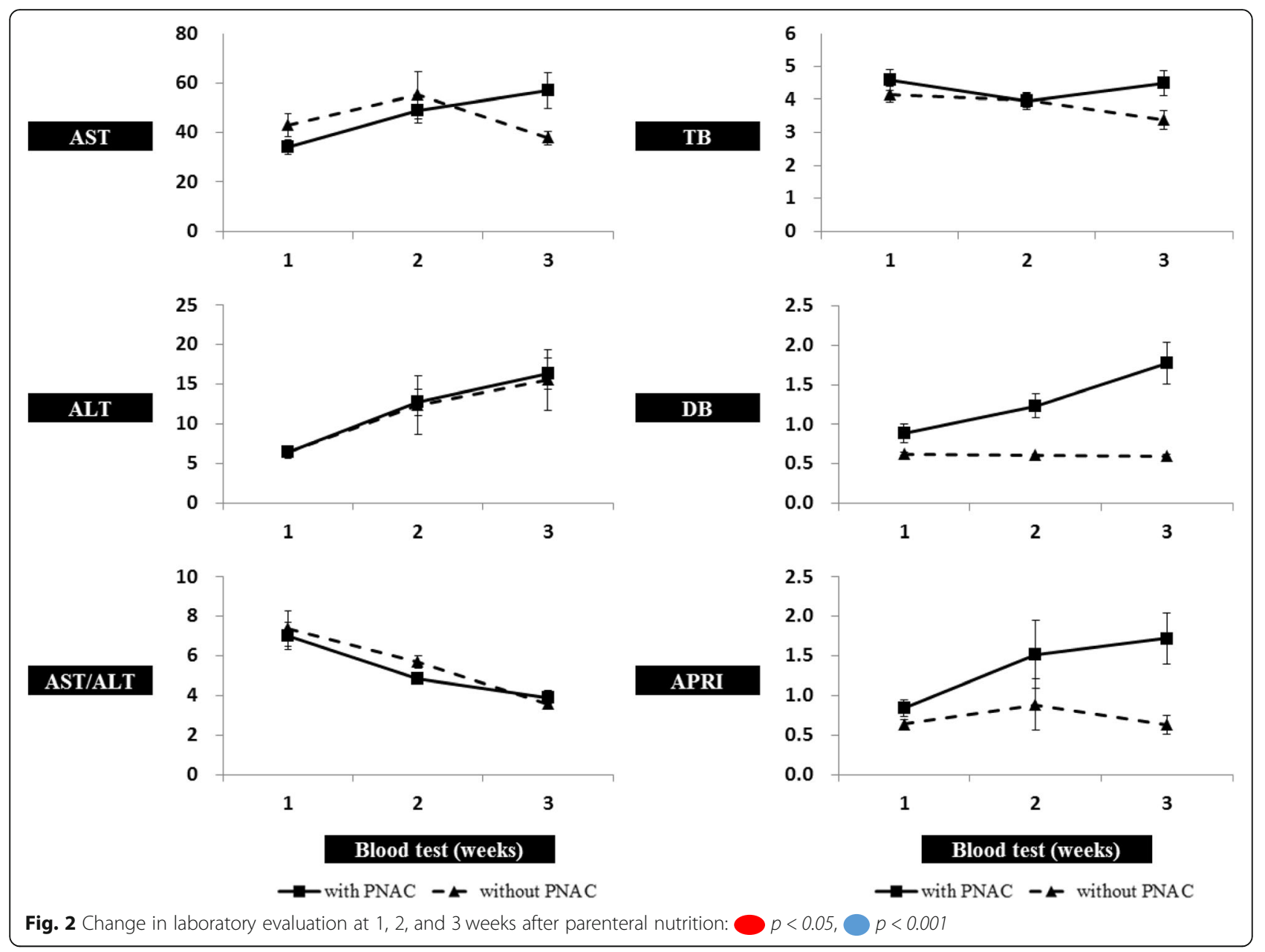

\section{Discussion}

$\mathrm{PN}$ is essential for survival in preterm infants. Especially, very low birth weight infants have to depend on support of PN for considerable time until establishment of enteral feeding [15]. Among the various clinical features of liver injury results from prolonged PN, PNAC is the most common clinical manifestation in preterm infants [17]. As increase survival of more preterm babies, incidence of PNAC also has increased. Although the precise incidence is still unknown, PNAC has become an emerging topic in neonatal intensive care units (NICUs) [18]. PNAC is an umbrella term that covers a wide spectrum from mild cholestasis or mild elevated liver enzyme to hepatic fibrosis, and cirrhosis. In some cases, the liver undergoes irreversible liver damage, end-stage liver failure, and eventually death $[19,20]$. Cyclic or intermittent $\mathrm{PN}$, fish-oil-based lipid emulsion use, and medications including ursodesoxycholic acid are suggested as treatments for PNAC [21, 22]. However, progressed hepatic failure results in mortality. Therefore, it is more important to stop the patient from developing irreversible terminal hepatic failure by preventing liver damage from long term PN. Hence, identification of risk groups for the development of PNAC is essential.

Liver biopsy is currently the gold standard in evaluating liver fibrosis and cirrhosis. However, considering the potential risks in performing liver biopsy, numerous efforts have been made to develop reliable and non-invasive methods for assessment of hepatic fibrosis and cirrhosis. This has led to the introduction of various biological markers, including APRI. Moreover, serial serological markers can be more reliable for reflecting changes of dynamic liver fibrosis. The APRI was initially introduced to monitor and evaluate the progression of fibrosis in adult patients with chronic hepatitis $C[23,24]$ and it has shown high accuracy in predicting both significant fibrosis and cirrhosis in also hepatitis B [25]. Therefore, it is widely used as a predictive marker to assume the degree of hepatic fibrosis in the adult population with other liver diseases [26, 27]. Moreover, the APRI is an indicator for liver function in end stage liver disease in the younger population $[8,9,11]$. In particular, among infants and children with biliary atresia or a short gut, APRI can predict liver function, liver survival, and prognosis $[7,10]$. Because 
Table 2 Associations with laboratory test results and development of PNAC

\begin{tabular}{|c|c|c|c|}
\hline \multirow{2}{*}{$\begin{array}{l}\text { Laboratory test } \\
\text { results at each } \\
\text { time point }\end{array}$} & \multicolumn{2}{|l|}{ PNAC } & \multirow[b]{2}{*}{$P$-value } \\
\hline & Yes & No & \\
\hline \multicolumn{4}{|l|}{1 week } \\
\hline AST (mg/dL) & $34.14 \pm 21.34$ & $43.09 \pm 51.40$ & $.821^{2}$ \\
\hline ALT (mg/dL) & $6.41 \pm 6.20$ & $6.45 \pm 4.56$ & $.414^{2}$ \\
\hline AST/ALT & $7.00 \pm 5.27$ & $7.37 \pm 9.76$ & $.867^{2}$ \\
\hline $\mathrm{TB}(\mathrm{mg} / \mathrm{dL})$ & $4.59 \pm 2.34$ & $4.16 \pm 2.47$ & $.119^{2}$ \\
\hline $\mathrm{DB}(\mathrm{mg} / \mathrm{dL})$ & $0.89 \pm 0.87$ & $0.63 \pm 0.24$ & $.015^{2}$ \\
\hline APRI & $0.84 \pm 0.81$ & $0.64 \pm 0.71$ & $.003^{2}$ \\
\hline $\operatorname{PLT}\left(\times 10^{3} / \mu \mathrm{L}\right)$ & $139.98 \pm 72.98$ & $191.55 \pm 70.45$ & $.000^{2}$ \\
\hline \multicolumn{4}{|l|}{2 weeks } \\
\hline AST & $48.77 \pm 38.47$ & $55.01 \pm 99.75$ & $.178^{2}$ \\
\hline $\mathrm{ALT}$ & $12.71 \pm 12.55$ & $12.32 \pm 38.79$ & $.218^{2}$ \\
\hline AST/ALT & $4.84 \pm 2.11$ & $5.70 \pm 3.28$ & $.394^{2}$ \\
\hline TB & $3.94 \pm 1.80$ & $3.98 \pm 2.49$ & $.603^{2}$ \\
\hline DB & $1.23 \pm 1.14$ & $0.60 \pm 0.25$ & $.000^{2}$ \\
\hline APRI & $1.52 \pm 3.23$ & $0.89 \pm 3.42$ & $.000^{2}$ \\
\hline PLT & $159.75 \pm 94.61$ & $263.46 \pm 114.66$ & $.000^{2}$ \\
\hline \multicolumn{4}{|l|}{3 weeks } \\
\hline AST & $57.04 \pm 49.33$ & $37.87 \pm 28.80$ & $.003^{2}$ \\
\hline ALT & $16.34 \pm 13.56$ & $15.52 \pm 39.85$ & $.011^{2}$ \\
\hline AST/ALT & $3.91 \pm 2.32$ & $3.60 \pm 1.99$ & $.569^{2}$ \\
\hline TB & $4.49 \pm 2.60$ & $3.38 \pm 2.86$ & $.004^{2}$ \\
\hline DB & $1.78 \pm 1.83$ & $0.59 \pm 0.31$ & $.000^{2}$ \\
\hline APRI & $1.72 \pm 2.26$ & $0.63 \pm 1.23$ & $.000^{2}$ \\
\hline PLT & $165.10 \pm 107.14$ & $285.34 \pm 143.80$ & $.000^{2}$ \\
\hline
\end{tabular}

All values are mean \pm standard deviation. APRI $(\%)=($ AST $/ 40) / P L T \times 100$ Shapiro-Wilk's test was employed for test of normality assumption Abbreviations: $T B$ total bilirubin, $D B$ direct bilirubin, $P L T$ platelets, AST aspartate aminotransferase, $A L T$ alanine transaminase, $A P R I$ aspartate aminotransferase/ platelet ratio index, PNAC parenteral nutrition-associated cholestasis

${ }^{1} P$ values were derived from chi-square test

${ }^{2} P$ values were derived from Mann-Whitney's $U$ test

of the differences in characteristics of the enrolled population and variables in the degree of liver fibrosis used as diagnostic criteria, there is a limit to the extent to which specific cut-off value of APRI can be defined. It is clear that levels of APRI are correlated with the progression of hepatic dysfunction and fibrosis in various hepatic diseases in children and adult patients. Only one study evaluated the APRI as a predictor for PNAC in premature infants to date [14]. Underwood et al. assessed 60 infants with gestational age $<34$ weeks, birth weight $<2000 \mathrm{~g}$ and intestinal perforation due to either NEC or spontaneous intestinal perforation. They reported that APRI was significantly different between 17 infants who later developed PNAC and another 43 infants who did not. They suggested the best APRI cut-point was 0.4775 within 2 weeks after perforation. In the current study, we enrolled ELBW infants on PN regardless of bowel perforation. We checked serial AST, ALT, total bilirubin, direct bilirubin, and APRI at 1,2, and 3 weeks after birth. Though the differences between infants with PNAC and without PNAC were more prominent with time, considering the statistical significance and values as predictors, we conclude that DB combined with APRI at 2 weeks of age was the most reliable indicator for the development of PNAC in ELBW infants. Because laboratory test results at 1 week had low statistical power and those at 3 weeks could not play a role as predictor; 14 infants were already diagnosed as having PNAC before 3 weeks of age. So, we finally analyzed 2 weeks laboratory test results and finally, the combined vales of $\mathrm{DB}$ and APRI has real high specificity; $\mathrm{DB}>0.7$ and APRI $>0.41$ showed a sensitivity of $50.0 \%$, specificity 91.8\%, PPV 75.7\%, and NPV 78.3\%.

Various methods including radiologic work-ups (ultrasound, computed tomography, elastography, magnetic resonance imaging) and serological biomarkers to predict hepatic fibrosis have been proposed. With these method results are encouraging, but it is difficult to perform in preterm infants, especially clinically unstable ELBW infants within the first few weeks. However, platelet counts and basic liver function tests including $T B, D B$, AST, and ALT are routinely performed in ELBW infants with PN at least once a week. The APRI can be calculated from two routine laboratory tests. Therefore, additional blood sampling or invasive procedures were not needed to evaluate APRI in these neonates, making the test more accessible within the NICU.

This study has some limitations. This study was conducted retrospectively, and therefore various clinical factors including the nutritional protocol, fluconazole prophylaxis and the types of PN solution were not uniformly applied to the study populations. However, these differences allowed us to compare the effects of different clinical factors on the development of PNAC. In addition, we did not perform the live biopsy. Hence, we could not determine a correlation between the biopsy results and APRI values. We also could not determine the exact cut-point value from this single study. However, we do believe that this study suggests the possibility of APRI as an early predictor for PNAC in ELBW infants on PN. Moreover, high specificity, PPV, and NPV of APRI than DB shows the priority of APRI as early predictor.

\section{Conclusion}

This study showed that APRI and DB values at 2 weeks of age had a reliable predictive value for the development of PNAC in ELBW infants. More research on this topic is warranted to help determine the specific values for predicting PNAC to be applied in clinical practice. 

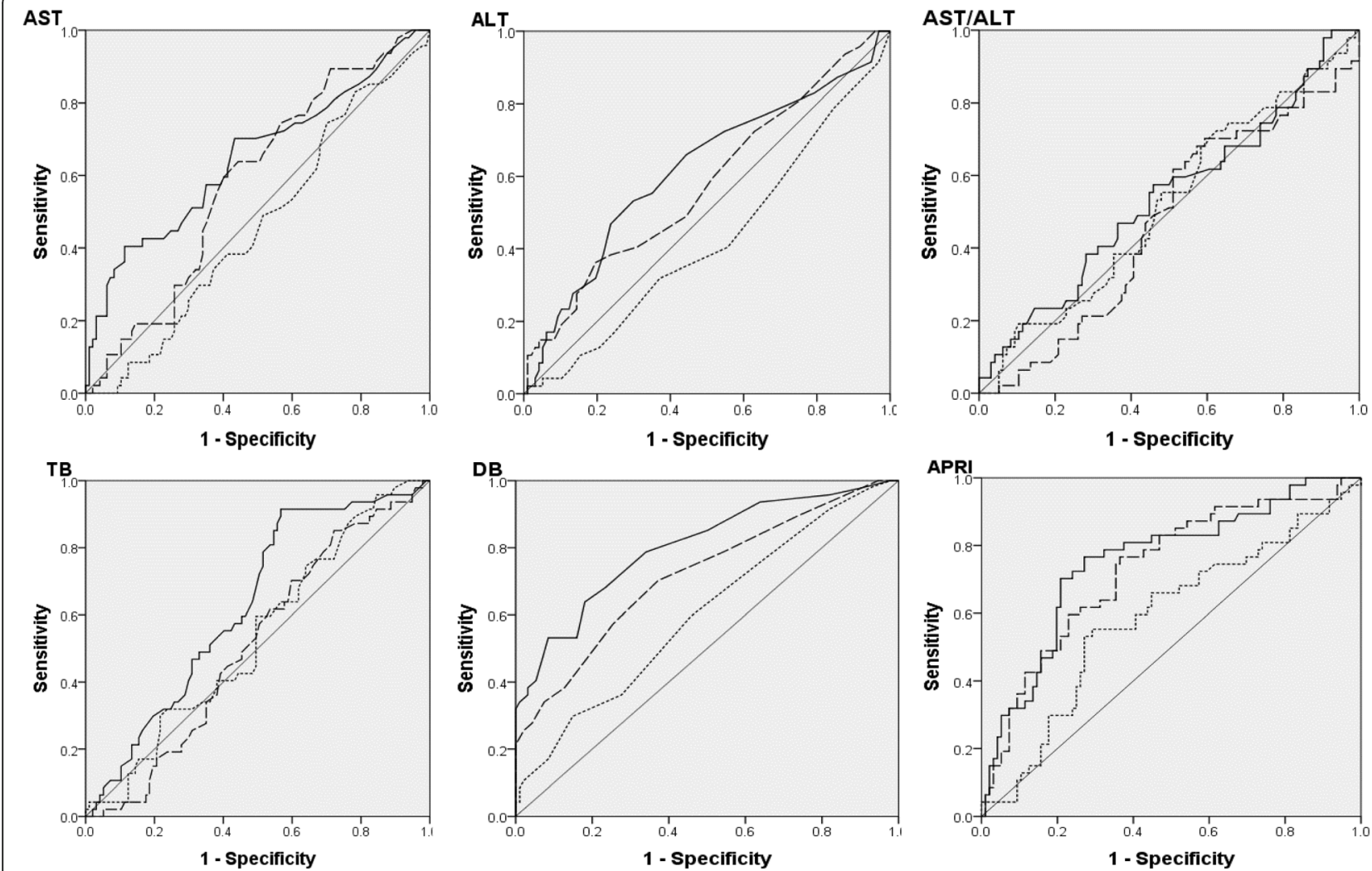

Fig. 3 Receiver operating characteristic curves of the laboratory test results to predict PNAC at time of 1 week (dotted line), 2 weeks (dashed line), and 3 weeks after PN (solid line). AUC: area under the curve. ${ }^{*} p<0.05$

Table 3 Multiple logistic regression analysis for risk factor of PNAC

\begin{tabular}{llll}
\hline Variables & OR & $95 \% \mathrm{Cl}$ & \\
\hline Hospital day & 1.01 & $(1.00-1.02)$ & .023 \\
Time to full enteral feeding $(120 \mathrm{cc} / \mathrm{kg} /$ day $)$ & 1.06 & $(1.02-1.09)$ & .001 \\
DB at 2 weeks & 23.63 & $(3.49-160.06)$ & .001 \\
APRI at 2 weeks & 3.37 & $(1.51-7.54)$ & .003 \\
\hline
\end{tabular}

Abbreviations: $A P R I$ aspartate aminotransferase/platelet ratio index, $D B$ direct bilirubin, $P N A C$ parenteral nutrition-associated cholestasis

Table 4 Predictive values for PNAC of laboratory evaluation at 2 weeks after PN

\begin{tabular}{|c|c|c|c|c|c|c|c|}
\hline & \multirow[t]{2}{*}{ Cut-point value } & \multicolumn{2}{|c|}{ PNAC } & \multirow[t]{2}{*}{ Sensitivity\% } & \multirow[t]{2}{*}{ Specificity\% } & \multirow{2}{*}{$\begin{array}{l}\text { PPV } \\
\%\end{array}$} & \multirow{2}{*}{$\begin{array}{l}\text { NPV } \\
\%\end{array}$} \\
\hline & & Yes & No & & & & \\
\hline \multirow[t]{2}{*}{ DB } & $>0.7$ & 32 & 27 & $57.1 \%$ & $75.2 \%$ & $54.2 \%$ & $77.4 \%$ \\
\hline & $\leq 0.7$ & 24 & 82 & & & & \\
\hline \multirow[t]{2}{*}{ APRI } & $>0.41$ & 43 & 42 & $76.8 \%$ & $62.2 \%$ & $50.6 \%$ & $84.1 \%$ \\
\hline & $\leq 0.41$ & 13 & 69 & & & & \\
\hline \multirow[t]{2}{*}{$\mathrm{DB}, \mathrm{APRI}$} & $>0.7$ and $>0.41$ & 28 & 9 & $50.0 \%$ & $91.7 \%$ & $75.7 \%$ & $78.1 \%$ \\
\hline & $\leq 0.7$ or $\leq 0.41$ & 28 & 100 & & & & \\
\hline
\end{tabular}




\section{Abbreviations}

ALT: Alanine aminotransferase; APRI: AST-to-platelet ratio index; AST: Aspartate aminotransferase; BPD: Bronchopulmonary dysplasia; DB: Direct bilirubin; ELBW: Extremely low birth weight; NEC: Necrotizing enterocolitis; NICU: Neonatal intensive care unit; NPV: Negative predictive value; PN: Parenteral nutrition; PNAC: Parenteral nutrition-associated cholestasis; PPV: Positive predictive value; ROC: Receiver operating characteristic; TB: Total bilirubin

\section{Acknowledgements}

This work was supported by a grant from Research year of Inje University in 20180018.

\section{Funding}

There are no funding resources relevant to this manuscript.

\section{Availability of data and materials}

We declare that the important data supporting the conclusions of this article are mostly described within the article, and the database is available from the corresponding author (forevery52@naver.com) on reasonable request.

\section{Authors' contributions}

$\mathrm{JH}$ was involved in the concept and design of the study and acquisition of the data. $\mathrm{JH}$ and $\mathrm{MC}$ collected data, performed the statistical analysis and interpret the data. MC participated in all steps of the study design, acquisition of data, and analysis and interpretation of the data. All authors approved the final version of the manuscript and made substantial contributions to all of the following: (1) the conception and design of the study, or acquisition of data, or analysis and interpretation of data, (2) drafting the article or revising it critically for important intellectual content, (3) final approval of the version to be submitted.

\section{Ethics approval and consent to participate}

This study was approved by institutional review board (IRB) of Inje University Haeundae Paik Hospital. The purpose of this study is to analyze the medical records of infants who have been discharged from the hospital and because of the lack of any artificial intervention in the diagnosis and treatment of the patients, consent to participates were not applicable. And it was waived the need for consent by IRB of Inje University Haeundae Paik Hospital.

\section{Consent for publication}

Not applicable.

\section{Competing interests}

The authors declare that they have no competing interests.

\section{Publisher's Note}

Springer Nature remains neutral with regard to jurisdictional claims in published maps and institutional affiliations.

Received: 15 December 2018 Accepted: 8 April 2019 Published online: 24 April 2019

\section{References}

1. Chaudhari S, Kadam S. Total parenteral nutrition in neonates. Indian Pediatr. 2006;43:953-64 https://www.ncbi.nlm.nih.gov/pubmed/17151398.

2. Btaiche IF, Khalidi N. Parenteral nutrition-associated liver complications in children. Pharmacotherapy. 2002;22:188-211 https://www.ncbi.nlm.nih.gov/ pubmed/11837558.

3. Tufano M, Nicastro E, Giliberti P, Vegnente A, Raimondi F, lorio R. Cholestasis in neonatal intensive care unit: incidence, aetiology and management. Acta Paediatr. 2009;98:1756-61 https://www.ncbi.nlm.nih.gov/pubmed/19664101.

4. Hsieh M, Pai W, Tseng H, Yang SN, Lu CC, Chen HL. Parenteral nutritionassociated cholestasis in premature babies: risk factors and predictors. Pediatr Neonatol. 2009;50:202-7 https://www.ncbi.nlm.nih.gov/pubmed/ 19856863.

5. Magnalat N, Bell C, Graves A, Imseis EM. Natureal history of conjugated bilirubin trajectory in neonates following parenteral nutrition cessation. BMC Pediatr. 2014;14:298 https://www.ncbi.nlm.nih.gov/pubmed/25492029.
6. Li SM, Li GX, Fu DM, Yu W, Dang L-Q. Liver fibrosis evaluation by ARFI and APRI in chronic hepatitis C. World J of Gastroenterol. 2014;20:9528-33 https:/www.ncbi.nlm.nih.gov/pubmed/25071348.

7. Suominen JS, Lampela H, Heikkilä P, Lohi J, Jalanko H, Pakarinen MP. APRi predicts native liver survival by reflecting portal fibrogenesis and hepatic neovascularization at the time of portoenterostomy in biliary atresia. J Pediatr Surg. 2015;50:1528-31 https://www.ncbi.nlm.nih.gov/pubmed/ 25783319.

8. Li B, Zhnag L, Zhang Z, Yan G, Zhu L, Lu W, Yu H. A noninvasive indicator for the diagnosis of early hepatitis B virus-related liver fibrosis. Eur J Gastroenterol Hepatol. 2018. https://doi.org/10.1097/MEG. 0000000000001281 https://www.ncbi.nlm.nih.gov/pubmed/30277926.

9. McGoogan KE, Smith PB, Choi SS, Berman W, Jhaveri R. Performance of the AST-to-platelet ratio index as a noninvasive marker of fibrosis in pediatric patients with chronic viral hepatitis. J Pediatr Gastroenterol Nutr. 2010;50: 344-6 https://www.ncbi.nlm.nih.gov/pubmed/20118806.

10. Grieve A, Makin E, Davenport M. Aspartate aminotransferase-to-platelet ratio index (APRi) in infants with biliary atresia: prognostic value at presentation. J Pediatr Surg. 2013:48:789-95 https://www.ncbi.nlm.nih.gov/pubmed/ 23583135.

11. Unlusoy Aksu A, Sari S, Yilmaz G, Eğritaş Gürkan Ö, Demirtaş Z, Dalgıç B. Aspartate aminotransferase-to-platelet ratio index in children with cholestatic liver diseases to assess liver fibrosis. Turk J Pediatr. 2015;57:492-7 https://www.ncbi.nlm.nih.gov/pubmed/27411417.

12. Beath SV, Kelly DA. Total parenteral nutrition-induced cholestasis: prevention and management. Clin Liver Dis. 2016;20:159-76 https://www.ncbi.nlm.nih. gov/pubmed/26593297.

13. Zambrno E, El-Hennawy M, Ehrenkranz RA, Reyes-Múgica M. Total parenteral nutrtion induced liver pathology: an autopsy series of 24 newborn cases. Pediatr Dev Pathol. 2004;7:425-32 11. https://www.ncbi.nlm.nih.gov/ pubmed/15547767.

14. Vongbhavit K, Underwood MA. Predictive value of the aspartate aminotransferase to platelet ratio index for parenteral nutrition-associated cholestasis in premature infants with intestinal perforation. J Parenter Eneteral Nutr. 2018;42:797-804 https://www.ncbi.nlm.nih.gov/pubmed/ 28792861.

15. Wai CT, Greenson JK, Fontana RJ, Kalbfleisch JD, Marrero JA, Conjeevaram HS, Lok AS. A simple noninvasive index can predict both significant fibrosis and cirrhosis in patients with chronic hepatitis C. Hepatology. 2003;38:51826 https://www.ncbi.nlm.nih.gov/pubmed/12883497.

16. Lee HH, Jung JM, Nam SH, Gina L, Chung ML. Risk factor analysis of parenterel nutrtion- associated cholestasis in extremely low birth weight infants. Acta Paediatr. 2016;105:313-9. https://www.ncbi.nlm.nih.gov/ pubmed/27097151.

17. Buchman A. Total parenteral nutrition-associated liver disease. J Parenter Enter Nutr. 2002;26:S43-8 https://www.ncbi.nlm.nih.gov/pubmed/12216721.

18. Willis TC, Carter BA, Rogers SP, Hawthorne KM, Hicks PD, Abrams SA. High rates of mortality and morbidity occur in infants with parenteral nutritionassociated cholestasis. J Parenter Enter Nutr. 2010;34:32-7 https://www.ncbi. nlm.nih.gov/pubmed/19587385.

19. Kubota A, Mochizuki N, Shiraishi J, Nakayama M, Kawahara H, Yoneda A Tazuke Y, Goda T, Nakahata K, Sano H, Hirano S, Kitajima H. Parenteralnutrition-associated liver disease after intestinal perforation in extremely low-birth weight infants: consequent lethal portal hypertension. Pediatr Int. 2013;55:39-43 https://www.ncbi.nlm.nih.gov/pubmed/23240986.

20. Hirano K, Kubota A, Nakayama M, Kawahara H, Yoneda A, Tazuke Y, Tani G, Ishii T, Goda T, Umeda S, Hirno S, Shiraishi J, Kitajima H. Parenteral nutrition-associated liver disease in extremely low-birthweight infants with intestinal disease. Pediatr Int. 2015;57:677-8 https://www.ncbi.nlm.nih.gov/pubmed/25728615.

21. Park HW, Lee NM, Kim JH, Kim KS, Kim SN. Parenteral fish-oil containing lipid emulsions may reverse parenteral nutrition-associated cholestasis in neonates: a systematic review and meta-analysis. J Nutr. 2015;145:277-83 https://www.ncbi. nlm.nih.gov/pubmed/25644348.

22. Hsiao CC, Lin HC, Chang YJ, Yang SP, Tsao LY, Lee CH, Chen HN, Chen JY, Tsai YG. Intravenous fish oil containing lipid emulsion attenuates inflammatory cytokines and the development of bronchopulmonary dysplasia in very premature infants: a double-blind, randomized controlled trial. Clin Nutr. 2018;18: 1-8 https:/www.ncbi.nIm.nih.gov/pubmed/29941233.

23. Calkins KL, Venick RS, Devaskar SU. Complications associated with parenteral nutrition in the neonate. Clin Perinatol. 2014;41:331-45 https://www.ncbi. nlm.nih.gov/pubmed/24873836. 
24. Shaheen AA, Myers RP. Diagnostic accuracy of the aspartate aminotransferase-to-platelet ratio index for the prediction of hepatitis Crelated fibrosis: a systematic review. Hepatology. 2007:46:912-21 https:// www.ncbi.nlm.nih.gov/pubmed/17705266.

25. Jin W, Lin Z, Xin Y, Jiang X, Dong Q, Xuan S. Diagnostic accurary of the aspartate aminotransferase to platelet ration index for the prediction of hepatitis B-related fibrosis: a leading meta-analysis. BMC Gastroenterol. 2012; 12:14 https://www.ncbi.nlm.nih.gov/pubmed/22333407.

26. Bang CS, Kang HY, Choi GH, Kim SB, Lee W, Song $\mathbb{H}$. The performance of serum biomarkers for predicting fibrosis in patients with chronic viral hepatitis. Korean J Gastroenterol. 2017;69:298-307 https://www.ncbi.nlm.nih. gov/pubmed/28539035.

27. Kruger FC, Daniels CR, Kidd M, Swart G, Brundyn K, van Rensburg C, Kotze M. APRI: a simple bedside marker for advanced fibrosis that can avoid liver biopsy in patients with NAFLD/NASH. S Afr Med J. 2011;101:477-80 https:// www.ncbi.nlm.nih.gov/pubmed/21920102.

Ready to submit your research? Choose BMC and benefit from:

- fast, convenient online submission

- thorough peer review by experienced researchers in your field

- rapid publication on acceptance

- support for research data, including large and complex data types

- gold Open Access which fosters wider collaboration and increased citations

- maximum visibility for your research: over $100 \mathrm{M}$ website views per year

At $\mathrm{BMC}$, research is always in progress.

Learn more biomedcentral.com/submissions 